\title{
Research Paper: Effect of Genu Varum Deformity on Gluteus Medius Muscle Activity and Postural Control During Single-Leg Jump-Landing
}

\author{
Yosef Mongashti Joni' ${ }^{1}$, Faraj Fatahi ${ }^{*}$, Narmin Ghanizadeh Hasar ${ }^{3}$, Eskandar Hosseinpour
}

1. Department of Sport Management, Faculty of Sport Sciences, Urmia University, Urmia, Iran.

2. Department of Sport Injuries and Corrective Exercises, Faculty of Physical Education, University of Isfahan, Isfahan, Iran.

3. Department of Sport Injuries and Corrective Exercises, Faculty of Sport Sciences, Urmia University, Urmia, Iran.

4. Department of Sport Management, Faculty of Physical Education and Sports Sciences, University of Tehran, Tehran, Iran.

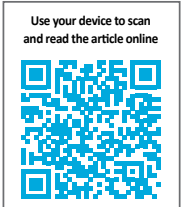

Ceftation: Mongashti Joni Y, Fatahi F, Ghanizadeh Hasar N, Hosseinpour E. Effect of Genu Varum Deformity on Gluteus Medius Muscle Activity and Postural Control During Single-Leg Jump-Landing. Physical Treatments. 2017; 7(2):79-88. http://dx.doi.org/10.32598/ptj.7.2.79

http://dx.doi.org/10.32598/ptj.7.2.79

Article info:

Received: 10 Nov 2016

Accepted: 26 Mar 2017

\begin{abstract}
A B S T RA C T
Purpose: Genu varum deformity changes the line of gravity from center of knee towards the medial side. This deviation results in changes in the upper part of the lower extremity that can affect postural control as well as the position and activity of the proximal muscles of the knee joint, like the gluteus medius muscle. Therefore this study aims to investigate the effect of genu varum disorder on the activity of gluteus medius muscle and postural control during single-leg jump-landing exercise.

Methods: A total of 28 male students of Physical Education Major (Mean [SD] age, weight, and height: $21.53[1.65] \mathrm{y}, 66.76[7.51] \mathrm{kg}$, and $173.38[4.54] \mathrm{cm}$, respectively) were enrolled and studied in two groups of genu varum (14 students) and normal ones (14 students). The activity level of gluteus medius muscle and the ground reaction force were measured using electromyography device and force plate, respectively in single-leg jump-landing exercise. In order to analyze the data, we used the Independent $t$ test at significance level of $\mathrm{P}<0.05$. Participants were asked to perform the single-leg jump-landing exercise with $50 \%$ of maximum vertical jump and land on the force plate using one leg. The RMS of gluteus medius muscle was measured using MATLAB software.

Results: There is a significant difference between the genu varum and normal group in terms of mean activity of gluteus medius muscle before and after the landing. There were significant difference between these groups with regard to time to stabilization in anterior-posterior direction, while significantly higher time to stabilization was found in the genu varum group compared to the normal groups in medial-lateral and overall direction. The time to stabilization of the subjects in the directions of medial-laterallateral and anterior-posterior and total Resultant Vector (RV) using the force plate in the jump-landing movement was evaluated. There was no significant difference in the time to stabilization between the two groups of the knee parenthesis and the normal knee in the anteriorposterior direction $(\mathrm{P}>0.05)$, but the time to stabilization in the medial-lateral and in resultant vector direction in the genu varum group was significantly more than those in normal knee group $(\mathrm{P}<0.05)$.

Conclusion: Participants with genu varum have weakness in postural stability in medial-lateral and total RV direction that might decrease the activity of gluteus medius muscle. This might increase the demand on the muscle for stabilizing hip and pelvis which decreases control of transverse and frontal part of hip and finally affects postural stability in medial-lateral direction (may be due to inappropriate activity of the hip). Thus, improvement of gluteus medius muscle might improve medial-lateral control of the posture in individuals with genu varum.
\end{abstract}

\section{* Corresponding Author:}

Faraj Fatahi, PhD

Address: Department of Sport Injuries and Corrective Exercises, Faculty of Physical Education, University of Isfahan, Isfahan, Iran

Phone: +98 (916) 6904293

E-mail: yosefmongashtijoni@gmail.com 


\section{Introduction}

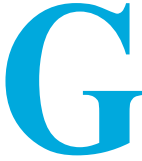

enu varum is known as one of the most common lower limb abnormalities. This abnormality affects postural control through producing pronation torque on the ankle and leg joints [1]. In normal standing mode, the center of gravity or the mechanical axis of the lower limb passes through the center of the knee joint, in such a way that the weight is roughly and evenly distributed over the medial and lateral parts of the knee [2]. In genu varum disorder, the direction of forces applying to the knee is changed which causes the gravity line moves to the medial part of the knee [3]. Genu varum abnormality changes the foot position, increases subtalar pronation joint torque during contact with the ground, and increases the postural sway [1, 4]. Previous research showed that people with genu varum have poor stability. Nyland et al. (2002) reported that genu varum abnormality affects the location of the center of pressure and mechanical balance control during the single-leg balance. The people with this abnormality use different posture dynamic control strategies during single-leg standing [5]. Samaei et al. (2012) also reported that genu varum abnormality increases posture sway in the medial-lateral directions in both static and dynamic modes, compared with those having normal knees [6].

Most studies conducted on stability in people with genu varum were conducted in a static state [5]. Kelby et al. [7] suggested that standing position does not effectively challenge nervous-muscular system in sports, recreational, or even in daily activities. The most dynamic types of activities, like jump-landing task may be a more accurate tool for evaluating the neuromuscular system during single-leg activities. Few studies that have been conducted in dynamic mode, used tests that lacked functional features [6]. When the relationship between muscle function and stability is considered, the main focus is usually on the muscles around the knee [8, 9]. However, the proximal muscular structure of the lower limb can play an important role in maintaining stability. Studies show that one of the important muscles in the function of individuals in balance, especially in single-leg movements is gluteus medius muscle $[10,11]$. Gluteus medius muscle is known as the main hip abductor and plays an important role in maintaining pelvic and trunk stability during single-leg exercises $[11,12]$. Inefficiency or weakness of this muscle during dynamic movements may affect the stability, especially on the frontal plane. Studies have shown that gluteus medius muscle stabilizes the pelvis during single-leg standing and plays an important role in controlling the kinematics of the hip joint [13]. Ineffi- ciency or weakness of this muscle during landing causes more medial adduction and lead to increase in the knee torque. Insufficient control of the musculoskeletal system on the pelvis due to the weakness of the gluteus medius muscle may affect the dynamic stability of postural control of the lower limbs [1].

Lee et al. (2012) reported that gluteus medius plays an important role in maintaining the dynamic postural stability in medial-lateral direction [14]. Since the abnormalities of the genu varum occurs on the frontal plane, it seems likely that changes in gluteus medius muscle activity are seen in patients with this deformity in order to maintain balance. However, in this regard, no research has been conducted. Considering what were discussed, the researchers in the present study aimed to investigate the changes in dynamic stability and the level of activity of the gluteus medius muscle in people with genu varum during the single-leg jump-landing task.

\section{Materials and Methods}

\section{Study subjects}

A total of 28 subjects (Mean[SD] age, weight, height, and BMI: 21.53[1.65] years, $66.76[7.15] \mathrm{kg}$, $173.38[4.54] \mathrm{cm}, 22.14[0.53] \mathrm{kg} / \mathrm{m}^{2}$, respectively) participated in this study in two groups of genu varum $(n=14)$ and normal knee $(n=14)$. Subjects with a history of neuromuscular-skeletal disorders, operation or fracture in the lower extremity over the past six months, and other lower limb abnormalities were excluded from the study. Before participation, the study protocol was explained to the subjects and they all signed the consent form. To evaluate the genu varum, the subjects were asked to put their legs together. If the distance between the two medial knee condyles in each subject was more than $3 \mathrm{~cm}$, he was considered as having genu varum knee [6]. Then the subjects were divided into groups according to their knees' condition.

\section{Data collection}

\section{Instrument}

Triaxial force plate (MIE model, manufactured by Bertec Corp, UK) was used for recording and measuring Ground Reaction Force (GRF). GRF was used to calculate the time to stabilization and detecting the first contact with the ground. Information regarding GRF was registered using the force plate at a sampling rate of 200 $\mathrm{Hz}$ [15]. The Sargent jumping device was used to measure the maximum vertical jump. The electromagnetic 


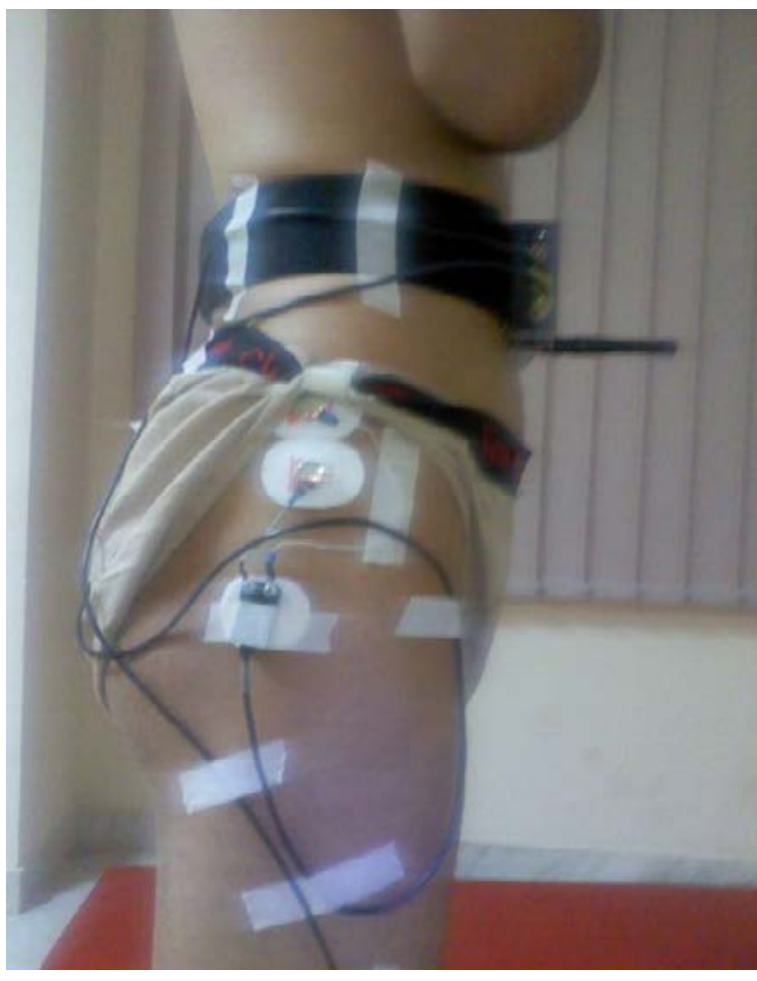

PHYSICAL TREA MENTS

Figure 1. Electrode locations on the gluteus medius muscle

data of gluteus medius muscle were collected using an electromyographic device (MIE model, Made in UK). This information was collected at $1000 \mathrm{~Hz}$ sampling rate [16]. To collect data simultaneously, the electromyographic device was synchronized with the force plate.

\section{Test run method}

After measuring and recording descriptive information of subjects, the hair over gluteus medius skin was shaved and the skin was cleansed with alcohol. Then dipole AGAGCL 10-mm diameter surface electrodes were placed (with the center-to-center distance of $2 \mathrm{~cm}$ ) on the bulk of the gluteus medius muscle. The electrodes were placed on half the distance between the greater trochanter and the outermost part of the iliac crest on the dominant leg parallel with the direction of the muscle fibers (Figure 1) [16]. To be ensured of the stability of the electrodes during the test, they were adhered with glue to the skin. We were paid special attention to the electrodes positions on the skin in order not to be dislocated. To investigate the correct location of the electrode, EMG muscle signals were evaluated during manual muscle testing.

\section{Jump-landing protocol}

To perform the jump-landing task on the force plate, initially it was necessary to calculate $50 \%$ of the maxi- mum vertical jump of the subjects. For this purpose, the subjects were given the maximum vertical jump test using the Sargent jump digital device. To perform this test, the subject stood under the Sargent jump digital device and raised his hands as much as possible without disconnecting his heels from the ground. This measurement was considered as the standing height of the subject. While the subjects were standing under the device with two feet, they were asked to do their maximum jump and land on two feet. This height was recorded as the maximum vertical jump. Each subject was asked to perform the vertical jump three times and after recording all three measures, the maximum number was recorded as the maximum vertical jump of the subject.

After this step, the maximum isometric contraction test of gluteus medius muscle was administered to normalize the EMG data. The subjects lied on the side for maximum contraction of gluteus medius muscle in a way that the dominant leg be on top and the entire body be placed in the same direction. The dominant leg hip had no abduction/adduction or medial/lateral rotation. To make the move better, the non-dominant leg was put in a bending position. Resistance was applied to avoid thigh abduction on the outside of the knee [17].

Then the subjects performed the jump-landing task. After measuring the maximum vertical jump of subjects and maximum voluntary contraction testing, the subjects were prepared to perform the jump-landing task. The maximum vertical jump of the subject was divided into two and $50 \%$ of the maximum vertical jump of the subject was calculated. Then a sign was marked next to the force plate device equivalent to $50 \%$ of the maximum jump of subjects. The subjects were trained to stand behind the mark placed $70 \mathrm{~cm}$ from the center of the force plate with bare feet [18]. Then they were asked to jump with two legs and touch the mark equivalent to a maximum of $50 \%$ jump with one hand and land on the plate with the dominant leg. The dominant leg selected as the leg the subjects used to shoot the ball. As soon as landing on the force pale, the subjects (who were already trained) put their hands over the pelvic area, hold their head high and look forward, and stand motionless for 20 seconds (Figure 1) [19]. If the subject hopped on the force plate, or touched the force plate with the other leg or did not touch the sign of $50 \%$ of maximum jump with the hand, that jump was discarded. Before executing the protocol, the subjects were allowed to practice the landing jump several times to get familiar with its conditions and procedure. Usually, the subjects needed to jump 3 to 5 times to know what to do. Each subject performed the jumplanding task three times. In order to prevent fatigue, 2 


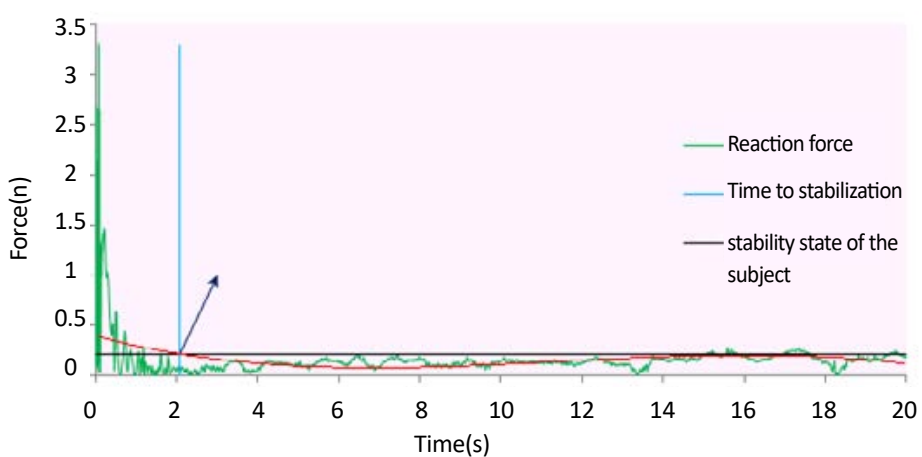

PHYSICAL TREATMENTS

Figure 2. Time to stabilization, ground reaction forces in the medial-lateral direction in the jump-landing task

minutes break was given between each task. Information regarding GRF was recorded by force plate simultaneous with the EMG data of gluteus medius muscle.

\section{Data analysis}

MATLAB software was used to calculate the time to stabilization. The time to medial-lateral and anterior-posterior stabilization was calculated by the range of variation method explained by Ross et al. [19]. To calculate the time to stabilization, the reaction forces at first two intervals of 5-10 and 10-15 seconds were considered. Then the range of these two intervals which include changes in reaction forces, were calculated and the range with smaller reaction forces variation was selected as the time interval in which the subject has a favorable stability. The largest number of this time interval is the horizontal line inserted over reaction forces. In fact, this horizontal line represents the stability state of the subject. Then, the force reaction data turned into absolute values and a cubic polynomial graph was placed over the components of the reaction force from the point of maximum reaction force. The time to stabilization in each component of the reaction force is the point where the third-order polynomial equation transects the horizontal line. MATLAB accurately calculated the time to stabilization by solving the third-order equation derived from the cubic polynomial graph equivalent to the horizontal line numbers over the reaction forces. The range of variation of GRF within the last 10 seconds of the single-leg stand of jump-landing task was calculated for medial-lateral and anterior-posterior components.

To control weight variable, the reaction forces in both directions were divided on subject's weight and was considered as the reference variable. The line of horizontal range variation, which shows the smallest complete range variation value of ground force reaction is inserted over the data.
Then the third-order polynomial graph was plotted. Time to stabilization in each components of the reaction force is the point where the cubic polynomial graph transects the horizontal variation range line (Figure 2).

Time to stabilization was calculated in all three times of the subject test in both Medial-Lateral (MLTTS) and Anterior-Posterior (APTTS) directions and then the average time in three runs was registered as the time to subject's stabilization in that direction. After calculating both APTTS and MLTTS, the Resultant Vector to stabilization (RVTTS) was calculated using the following formula:

$$
\text { RVTTS }=\sqrt{M_{L T T S^{2}}+\text { APTTS }^{2}}
$$

Although the time to stabilization in the Anterior-Posterior (APTTS) and Medial-Lateral (MLTTS) directions are usually reported separately, recently, the Resultant Vector to stabilization (RVTTS) variable is reported too to provide a unified stability assessment from both movement planes [20]. It is believed that an overall stability index is the best determinant of the general ability of individuals to maintain balance [21]. Average values of the Resultant Vector to stabilization (RVTTS) were calculated for each subject.

Electromyographic data processing was done by MATLAB mathematical software. For analysis of raw electromagnetic waves, the RMS calculation method has been used. To show muscle activity during single-leg jump-landing task, RMS electromyography data were collected from $100 \mathrm{~ms}$ before [11] and $200 \mathrm{~ms}$ after the first contact of the foot with the ground [16].

Time interval of $100 \mathrm{~ms}$ before and $200 \mathrm{~ms}$ after landing was selected, because muscle activity before landing is a predictive measure of muscle contractility. Before the foot touches the ground on the landing motion, the muscles of the lower limbs are activated to absorb 
the contact forces. In order to reduce the amount of GRF, the body should predict landing and be prepared through muscle contraction. Inability of the body to produce eccentric and predictive contractions of lower limb muscles dramatically increases GRF and also the time to stabilization.

The initial contact of foot with the ground is defined as the time in which the force plate shows the vertical component of the ground force reaction [10].

RMS was calculated using the maximum isometric volumetric contraction data at the same time interval (100 and $200 \mathrm{~ms}$ ). Then the RMS was normalized by dividing RMS before and after the contact over the maximum isometric voluntary contraction. Electromyographic information was filtered by high-pass and low-pass filters.

\section{Statistical analysis}

The mean values of the time components to overall, anteriorposterior, and medial-lateral stabilization between research groups were compared using $\mathrm{t}$ test. The Multivariate Analysis of Variance (MANOVA) was used to compare muscle activity levels between two groups. SPSS version 19 was used for data analysis. Alpha level of $\mathrm{P}<0.05$ was used for all statistical tests.

\section{Results}

\section{Time to stabilization}

There was no significant difference with regard to demographic data, which include age, height, and weight between the subjects (Table 1). Times to overall, mediallateral and anterior-posterior stabilizations are presented in test groups. Comparing the values of the time to recorded stabilization showed no significant difference between the two groups in the anterior-posterior direction ( $\mathrm{P}>0.05$ ). But, time to stabilization in the medial-lateral and the overall state in the genu varum group was significantly higher than those in the normal knee group $(\mathrm{P}<0.05)$ (Table 2).

\section{Gluteus medius muscle activity}

The activity level of the gluteus medius muscle at 100 $\mathrm{ms}$ before and $200 \mathrm{~ms}$ after the initial contact in the nor-

Table 1. Demographic data of subjects and the distance between the knees

\begin{tabular}{|c|c|c|c|c|}
\hline Variable & $\begin{array}{c}\text { Genu Varum Group }(n=14) \\
\text { Mean } \pm S D\end{array}$ & $\begin{array}{l}\text { Normal Knee Group }(n-14) \\
\text { Mean } \pm S D\end{array}$ & T Value & Sig. \\
\hline Weight (kg) & $67.3 \pm 6.99$ & $66.23 \pm 8.25$ & 0.95 & 0.29 \\
\hline Height $(\mathrm{cm})$ & $1717.76 \pm 3.74$ & $175 \pm 4.83$ & 0.98 & 0.33 \\
\hline Age (y) & $21.3 \pm 1.88$ & $21.76 \pm 1.42$ & 1.50 & 0.11 \\
\hline Knees distance $(\mathrm{cm})$ & $5.42 \pm 1.98$ & $0.857 \pm 0.60$ & 6.50 & 0.02 \\
\hline
\end{tabular}

PHYSICAL TREA $\ M E N T S$

Table 2. The average time to stabilization, F value and level of significance of study subjects

\begin{tabular}{|c|c|c|c|c|}
\hline Time to Stabilization & $\begin{array}{l}\text { Genu Varum Group }(n=14), \\
\text { Mean } \pm S D\end{array}$ & $\begin{array}{l}\text { Normal Knee Group }(n-14) \text {, } \\
\text { Mean } \pm S D\end{array}$ & F Value & Sig. \\
\hline MLTTS & $3.167 \pm 1.75$ & $2.072 \pm 0.637$ & 1.086 & 0.037 \\
\hline APTTS & $3.266 \pm 0.484$ & $3.238 \pm 0.371$ & 0.598 & 0.867 \\
\hline RVTTS & $4.668 \pm 1.44$ & $3.813 \pm 0.433$ & 1.197 & 0.043 \\
\hline
\end{tabular}

PHYSICAL TREA $\mid$ MENTS

Table 3. Gluteus medius activity level $100 \mathrm{~ms}$ before and $200 \mathrm{~ms}$ after the ground contact $(\mathrm{mV})$

\begin{tabular}{cccc}
\hline Level of Activity & $\begin{array}{c}\text { Normal Knee Group }(n=14) \\
\text { Mean } \pm \text { SD }\end{array}$ & $\begin{array}{c}\text { Genu Varum Group }(n=14) \\
\text { Mean } \pm \text { SD }\end{array}$ & F Value \\
\hline Before contact & $0.605984 \pm 0.118$ & $0.48323 \pm 0.137$ & 6.432 \\
After contact & $0.775532 \pm 0.114$ & $0.680653 \pm 0.121$ & 4.507 \\
\hline
\end{tabular}




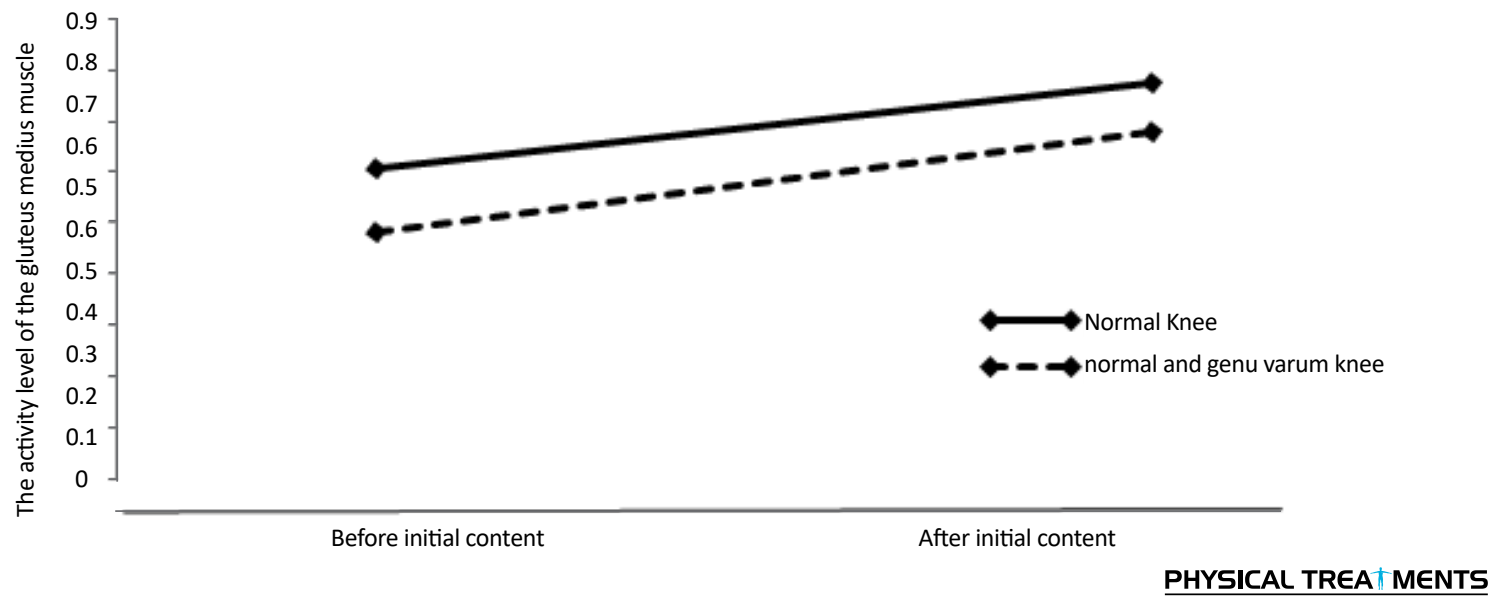

Figure 3. Average level of activity of gluteus medius before and after contact with the ground in the normal and genu varum groups

mal knee group was significantly higher than that of genu varum group $(\mathrm{P}<0.05)$ (Table 3 ). In addition, the activity level of the gluteus medius muscle in both groups after the first contact was significantly more than that before the first contact (Figure 3 and 4).

\section{Discussion}

The findings of this study showed that genu varum deformity affects dynamic stability index in the mediallateral and overall stability index during single-leg jumplanding task, but it does not affect the anterior-posterior stability index. Samaei et al. (2012) reported that people with genu varum have lower dynamic and static stability in the medial-lateral direction, but their overall dynamic and static stability and the anterior-posterior stability were not different from normal knee subjects [6]. Nyland et al. (2002) also reported that people with genu varum use different dynamic postural control strategies during single-leg standing [5]. According to these studies, genu varum disrupts stability. Though previous studies have investigated the effect of genu varum a on the postural control, but a few research studies conducted in relation to stability in these individuals, have used tests which are either done in static mode [5] or tests which have not been largely functional [6]. In the present research, the jumplanding test has been used which is a common movement of many sports and is a completely functional exercise.

Our results showed that postural sway in the anteriorposterior direction (Sagittal plane) may not be affected by genu varum deformity, while stability in the medial-lateral direction (frontal plane) can be affected by this abnormality. Genu varum abnormality occurs on the frontal plane. Therefore, it is logical that there would be no effect in the anterior-posterior directions with regard to the time to stabilization for the genu varum abnormality, because this abnormality affects more the medial-lateral movements than the anterior-posterior movements. But in the medial-lateral direction, the time to stabilization of the genu

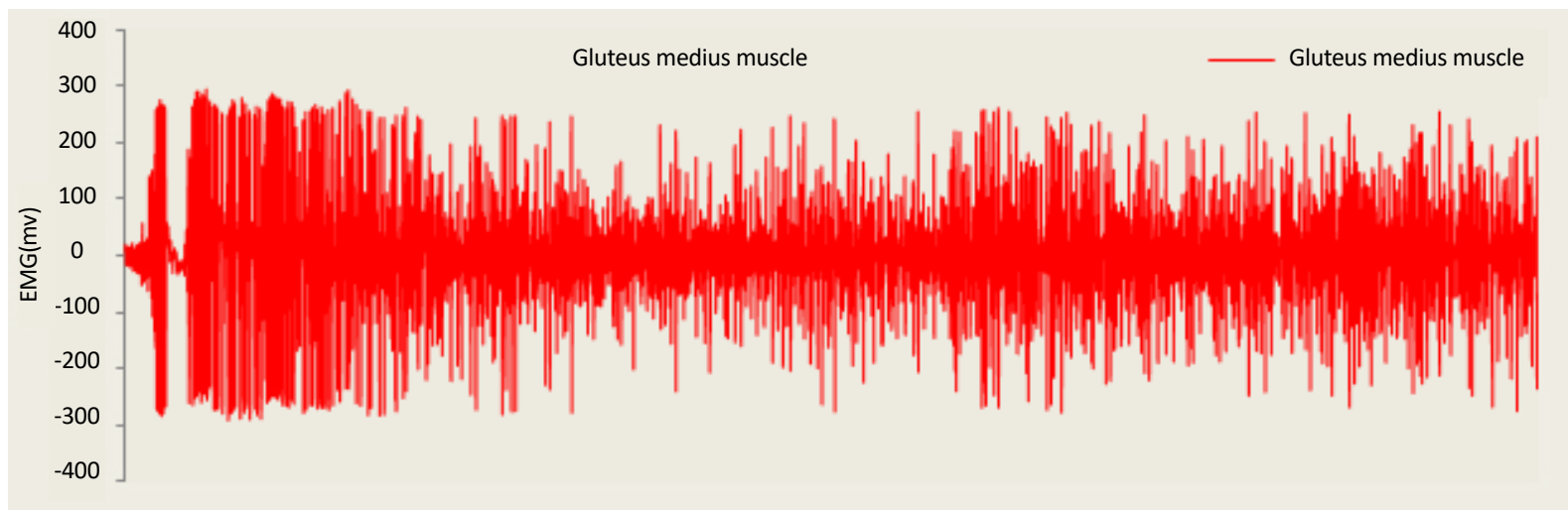

PHYSICAL TREA MENTS

Figure 4. Part of the recorded electromyography of the gluteus medius muscle in the jump-landing task 
varum group was more than normal knee group and the difference was significant. Time to stabilization in general stability mode in the genu varum group was more than normal knee group and the difference was also significant.

Time to stabilization in general stability state is influenced by both medial-lateral and anterior-posterior directions, but in this study the effect of medial-lateral direction was more on this state which made the time to stabilization to be significant between the two groups in this case. Stability is affected by various factors. One of these factors is weak neuromuscular control [22, 23]. Therefore, one of the reasons for the weaker stability in the genu varum group is the lower muscle activity, however, the role of certain muscle groups for the balance is not well defined. Moreover, little attention is paid to the role of the muscles surrounding the hip in dynamic stability. Our main finding was that EMG activity of gluteus medius muscle before and after landing in the normal knee group was significantly more than that the genu varum group. We investigated muscle activity before and after landing for several reasons. Muscle activity before landing is a measure of contractility of the predictive muscle. While delayed muscle response to stretch stimulation is related to the response time necessary to react appropriately to the knee abduction. Proactive muscle activity is an important variable which should be considered. Muscle activity after landing, how muscles respond to forces, and applied torques occur as a result of the GRF [16].

Gluteus medius muscle is the main abductor of the hip and is essential for hip stability. Improper function of this muscle will result in the lower limb dynamic dysfunction during single-leg standing [11]. From a biomechanical point of view, gluteus medius moment arm is longer than other muscles of the lower limb (i.e., invertor and evertor muscles) which control the movement of the frontal plane. Also hip abductors are effective in changing the center of gravity in response to medial-lateral disturbances [24, 25]. For example, Gribble et al. reported that fatigue of the hip muscles leads to a reduced function of one-leg standing balance, particularly in the medial-lateral direction [26]. Also, Miller et al. reported that proximal muscles are more important than the distal muscles of the ankle in maintaining the center of gravity [27]. In addition, Hubbard et al. reported that function of the hip abductor muscles is related to dynamic balance function in adults [28]. Moreover, Lee et al. (2012) reported that gluteus medius muscle is associated with the dynamic stability in medial-lateral direction [14].

People with genu varum show lower gluteus medius activity compared to that in normal people. This may pre- vent proper pelvic stability during landing and increase dynamic deviation from normal stance which leads to dynamic postural instability. Therefore, the observed difference in the level of gluteal activity could be responsible for the differences observed in postural stability in the medial-lateral direction between two groups. Genu varum may modify the function of the gluteus medius muscle. A few studies have investigated the direct effect of the genu varum on gluteal function. It was shown that genu varum leads to an increase in the medial rotation of the femur [29, 30]. This medial rotation may modify the function of the gluteus medius muscle and reduce the control over the hip and increase the dynamic deviation of the lower limbs from normal stance during functional activities [31]. Increased medial femoral rotation probably leads to higher demand for power generation to control the hip and pelvis and reduced activity of the gluteus medius muscle may decrease frontal and transverse planes control during functional activities. The relationship between genu varum and gluteus medius muscle may be explained through the effect of this abnormality on the moment arm level of the muscles. Standing on single leg requires hip abductors to generate high abducting power to maintain pelvic stability, because the gluteus medius moment arm is smaller than the body arm moment working in the hip [32]. If genu varum reduces the effect and force produced by this muscle, attaining pelvic stability may become very difficult.

Overall, our findings showed that people with genu varum have weak postural stability in general and the medial-lateral directions. These findings also showed that genu varum may reduce the activity of the gluteus medius muscle. This can increase the demand on the muscle for maintaining hip and pelvic stability. These biomechanical and neuromuscular changes may reduce the control over the transverse and frontal planes of the hip and affect the postural stability in the medial-lateral direction. Weaker postural stability in people with genu varum in the medial-lateral direction in dynamic movements can be due to the inappropriate activity of the hip. Therefore, improvement of the gluteus medius muscle function may improve the control of medial-lateral posture in people with genu varum.

\section{Acknowledgements}

This study is based on a master's degree thesis from the University of Isfahan. Therefore, thanks to the cooperation of the officials of the Faculty of Physical Education of the University of Isfahan who helped us to use the lab and also thank all the participants in this study. 


\section{Conflict of Interest}

The authors declared no conflicts of interest.

\section{References}

[1] Van Gheluwe B, Kirby KA, Hagman F. Effects of simulated genu valgum and genu varum on ground reaction forces and subtalar joint function during gait. Journal of the American Podiatric Medical Association. 2005; 95(6):531-41. doi $10.7547 / 0950531$

[2] Johnson F, Leitl S, Waugh W. The distribution of load across the knee. A comparison of static and dynamic measurements. The Journal of Bone and Joint Surgery British volume. 1980; 62-B(3):346-9. doi: 10.1302/0301-620x.62b3.7410467

[3] Witvrouw E, Danneels L, Thijs Y, Cambier D, Bellemans J. Does soccer participation lead to genu varum. Knee Surgery, Sports Traumatology, Arthroscopy. 2009; 17(4):422-7. doi: 10.1007/s00167-008-0710-z

[4] Subotnick SI. Podiatric sports medicine. Hoboken, N.J.: Wiley-Blackwell; 1975.

[5] Nyland J, Smith S, Beickman K, Armsey T, Caborn DNM. Frontal plane knee angle affects dynamic postural control strategy during unilateral stance. Medicine \& Science in Sports \& Exercise. 2002; 34(7):1150-7. doi: 10.1097/00005768200207000-00016

[6] Samaei A, Bakhtiary A, Elham F, Rezasoltani A. Effects of genu varum deformity on postural stability. International Journal of Sports Medicine. 2012; 33(6):469-73. doi: 10.1055/ s-0031-1301331

[7] Colby SM, Hintermeister RA, Torry MR, Steadman JR. Lower limb stability with ACL impairment. Journal of Orthopaedic \& Sports Physical Therapy. 1999; 29(8):444-54. doi: 10.2519/jospt.1999.29.8.444

[8] Ikezoe T, Asakawa Y, Tsutou A. The relationship between quadriceps strength and balance to fall of elderly admitted to a nursing home. Journal of Physical Therapy Science. 2003; 15(2):75-9. doi doi: 10.1589/jpts.15.75

[9] Moxley Scarborough D, Krebs DE, Harris BA. Quadriceps muscle strength and dynamic stability in elderly persons. Gait \& Posture. 1999; 10(1):10-20. doi: 10.1016/s09666362(99)00018-1

[10] Hart JM, Garrison JC, Kerrigan DC, Palmieri-Smith R, Ingersoll $\mathrm{CD}$. Gender differences in gluteus medius muscle activity exist in soccer players performing a forward jump. Research in Sports Medicine. 2007; 15(2):147-55. doi: $10.1080 / 15438620701405289$

[11] Russell KA, Palmieri RM, Zinder SM, Ingersoll CD. Sex differences in valgus knee angle during a single-leg drop jump. Journal of athletic training. 2006; 41(2):166-71. PMCID PMC1472649

[12] Earl JE. Gluteus medius activity during 3 variations of isometric single-leg stance. Journal of Sport Rehabilitation. 2005; 14(1):1-11. doi: 10.1123/jsr.14.1.1
[13] Horak FB. Clinical measurement of postural control in adults. Physical Therapy. 1987; 67(12):1881-5. doi: 10.1093/ ptj/67.12.1881

[14] Lee SP, Souza RB, Powers CM. The influence of hip abductor muscle performance on dynamic postural stability in females with patellofemoral pain. Gait \& Posture. 2012; 36(3):425-9. doi: 10.1016/j.gaitpost.2012.03.024

[15] Gribble PA, Mitterholzer J, Myers AN. Normalizing considerations for time to stabilization assessment. Journal of Science and Medicine in Sport. 2012; 15(2):159-63. doi: 10.1016/j.jsams.2011.07.012

[16] Carcia CR, Martin RL. The influence of gender on gluteus medius activity during a drop jump. Physical Therapy in Sport. 2007; 8(4):169-76. doi: 10.1016/j.ptsp.2007.06.002

[17] Ayotte NW, Stetts DM, Keenan G, Greenway EH. Electromyographical analysis of selected lower extremity muscles during 5 unilateral weight-bearing exercises. Journal of Orthopaedic \& Sports Physical Therapy. 2007; 37(2):48-55. doi: 10.2519/jospt.2007.2354

[18] Kaminski TW, Ross SE, Guskiewicz KM. Time to stabilization: a method for analyzing dynamic postural stability. Ath letic Therapy Today. 2003; 8(3):37-9. doi: 10.1123/att.8.3.37

[19] Ross SE, Guskiewicz KM, Yu B. Single-leg jump-landing stabilization times in subjects with functionally unstable ankles. Journal of athletic training. 2005; 40(4):298-304. PMCID: PMC1323291

[20] Ross SE, Guskiewicz KM, Gross MT, Yu B. Assessment tools for identifying functional limitations associated with functional ankle instability. Journal of Athletic Training. 2008; 43(1):44-50. doi: 10.4085/1062-6050-43.1.44

[21] Perron M, Hébert LJ, McFadyen BJ, Belzile S, Regnieàre M. The ability of the Biodex Stability System to distinguish level of function in subjects with a second-degree ankle sprain. Clinical Rehabilitation. 2007; 21(1):73-81. doi $10.1177 / 0269215506071288$

[22] Prentice WE. Rehabilitation techniques for sports medicine and athletic training with laboratory manual and esims password card. $4^{\text {th }}$ edition. New york: McGraw-Hill Humanities; 2004

[23] Orr R. Contribution of muscle weakness to postural instability in the elderly. European Journal of Physical and Rehabilitation Medicine. 2010; 46(2):183-220. PMID: 20485224

[24] Winter DA, Prince F, Frank JS, Powell C, Zabjek KF. Unified theory regarding $\mathrm{A} / \mathrm{P}$ and $\mathrm{M} / \mathrm{L}$ balance in quiet stance. Journal of Neurophysiology. 1996; 75(6):2334-43. doi: 10.1152/jn.1996.75.6.2334

[25] Hoy MG, Zajac FE, Gordon ME. A musculoskeletal model of the human lower extremity: The effect of muscle, tendon, and moment arm on the moment-angle relationship of musculotendon actuators at the hip, knee, and ankle. Journal of Biomechanics. 1990; 23(2):157-69. doi: 10.1016/00219290(90)90349-8

[26] Gribble PA, Hertel J. Effect of lower-extremity muscle fatigue on postural control. Archives of Physical Medicine and Rehabilitation. 2004; 85(4):589-92. doi: 10.1016/j. apmr.2003.06.031 
[27] Miller PK, Bird AM. Localized muscle fatigue and dynamic balance. Perceptual and Motor Skills. 1976; 42(1):135-8. doi: 10.2466/pms.1976.42.1.135

[28] Hubbard TJ, Kramer LC, Denegar CR, Hertel J. Correlations among multiple measures of functional and mechanical instability in subjects with chronic ankle instability. Journal of Athletic Training. 2007; 42(3):361-6. PMCID: PMC1978473

[29] Kendall FP, McCreary EK, Provance PG. Muscles: Testing and function with posture and pain. Baltimore: Lippincott Williams \& Wilkins; 2005

[30] Sahrmann S. Movement system impairment syndromes of the extremities, cervical and thoracic spines. Amsterdam: Elsevier; 2011

[31] Nyland J, Kuzemchek S, Parks M, Caborn DNM. Femoral anteversion influences vastus medialis and gluteus medius EMG amplitude: composite hip abductor EMG amplitude ratios during isometric combined hip abduction-external rotation. Journal of Electromyography and Kinesiology. 2004; 14(2):255-61. doi: 10.1016/s1050-6411(03)00078-6

[32] Neumann DA. Kinesiology of the musculoskeletal system: Foundations for physical rehabilitation. Philadelphia: Mosby; 2002. 
